Saudi Journal of Medical and Pharmaceutical Sciences

Abbreviated Key Title: Saudi J Med Pharm Sci ISSN 2413-4929 (Print) |ISSN 2413-4910 (Online) Scholars Middle East Publishers, Dubai, United Arab Emirates

Journal homepage: https://saudijournals.com/sjmps

Original Research Article

\title{
A Study on Comparision of Quality of Life of Asthma Patient with PFT and Mini AQLQ Scoring in SRMC
}

\author{
${ }^{1}$ Assitant Professor, Department of Pulmonary Medicine, Sri Ramachandra Medical College, Chennai \\ ${ }^{2}$ Postgraduate, Department of Pulmonary Medicine, Sri Ramachandra Medical College, Chennai \\ ${ }^{3,4}$ B.Sc, Allied Health Sciences(Respiratory),Sri Ramachandra Medical College, Chennai \\ ${ }^{5}$ HOD, Department of Pulmonary Medicine,Sri Ramachandra Medical College, Chennai
}

Dr. Sindhura Koganti ${ }^{1}$, Dr. Inba Shyamala ${ }^{2^{*}}$, Niveditha $\mathrm{N}^{3}$, Hariprita D.P. ${ }^{4}$, Dr. Prof. C. Chandrasekar ${ }^{5}$

DOI: $10.36348 /$ sjmps.2020.v06i01.017

| Received: 03.01.2020 | Accepted: 19.01.2020 | Published: 30.01.2020

*Corresponding author: Dr. Inba Shyamala R

\section{Abstract}

Asthma is one of the chronic respiratory conditions. A large Number of patients still experience a high level of morbidity .Much of the morbidity from Asthma is believed to be due to factors such as a chronic condition, poor knowledge of the disease process and medication understanding on the use of and poor self-management. Patient education is becoming an essential area of service provision. In this study30 Patients who were diagnosed as asthma with PFT and attending Pulmonology OPD at SRMC were included and were given a mini AQLQ questionnaire containing 15 questions regarding the level of asthma and limitations of activities, to test their knowledge about Asthma and quality of life, with particular reference to the knowledge about the disease and answers were analyzed to test the knowledge of the Patients about Asthma. It was done twice, first visit and after 3 weeks. These patients were prescribed with bronchodilators (SABA or LABA), Breathing exercises were explained and Inhaler technique was checked and proper technique is taught to the patient. Results showed Educating the patient about disease and teaching inhaler technique, breathing exercise resulted in more improvement in both PFT and quality of life of asthma patients with significant improvement in lung function.

Keywords: Asthma, Lung function test, breathing exercise, Quality of life, Morbidity, Inhaler technique, Bronchodilators.

Copyright @ 2020: This is an open-access article distributed under the terms of the Creative Commons Attribution license which permits unrestricted use, distribution, and reproduction in any medium for non-commercial use (NonCommercial, or CC-BY-NC) provided the original author and source are credited.

\section{MATERIALS AND Methods}

30 Patients who were diagnosed as asthma with PFT and attending Pulmonology OPD at SRMC were included in the study.

All the Patients were given a mini AQLQ questionnaire containing 15 questions regarding the level of asthma and limitations of activities, to test their knowledge about Asthma and quality of life, with particular reference to the knowledge about the disease and answers were analyzed to test the knowledge of the Patients about Asthma.

During the first visit patients PFT was done to all the patients. These patients were prescribed with bronchodilators (SABA or LABA), Breathing exercises were explained and Inhaler technique was checked and proper technique is taught to the patient.

Efficacy was measured on the basis of PULMONARY FUNCTION TEST (PFT) and mini AQLQ questionnaire on the $1^{\text {st }}$ visit and patients are instructed to visit on the $3^{\text {rd }}$ week when the PFT and mini AQLQ questionnaire were taken again.

The data entry and analysis were done using MS excel -windows 10 software. The percentiles and 'p' values were also calculated. Wilcoxon signed ranks test and T-test were done to compare the pre and post mini AQLQ and FEV1 values. 


\section{RESULTS}

\begin{tabular}{|c|c|c|}
\hline \multicolumn{2}{|c|}{} & N \\
\hline \multirow{4}{*}{ AQLQrecoded2- } & Negative Ranks & $\mathbf{3}^{\mathbf{a}}$ \\
\cline { 2 - 3 } AQLQrecoded1 & Positive Ranks & $\mathbf{2 1}^{\mathbf{b}}$ \\
\cline { 2 - 3 } & Ties & $6^{\mathrm{c}}$ \\
\cline { 2 - 3 } & & 30 \\
\cline { 2 - 3 } & Total & \\
\hline
\end{tabular}
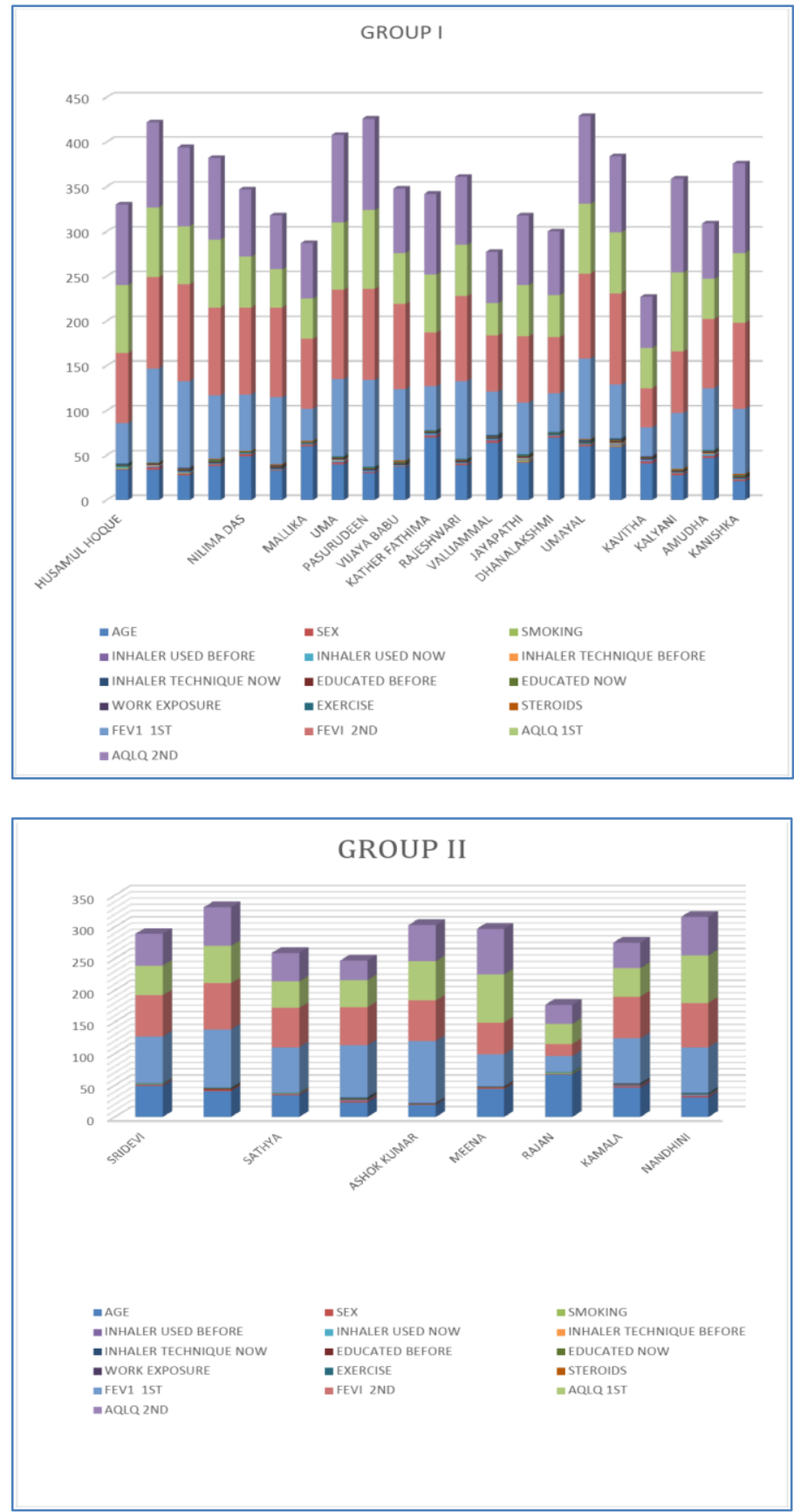

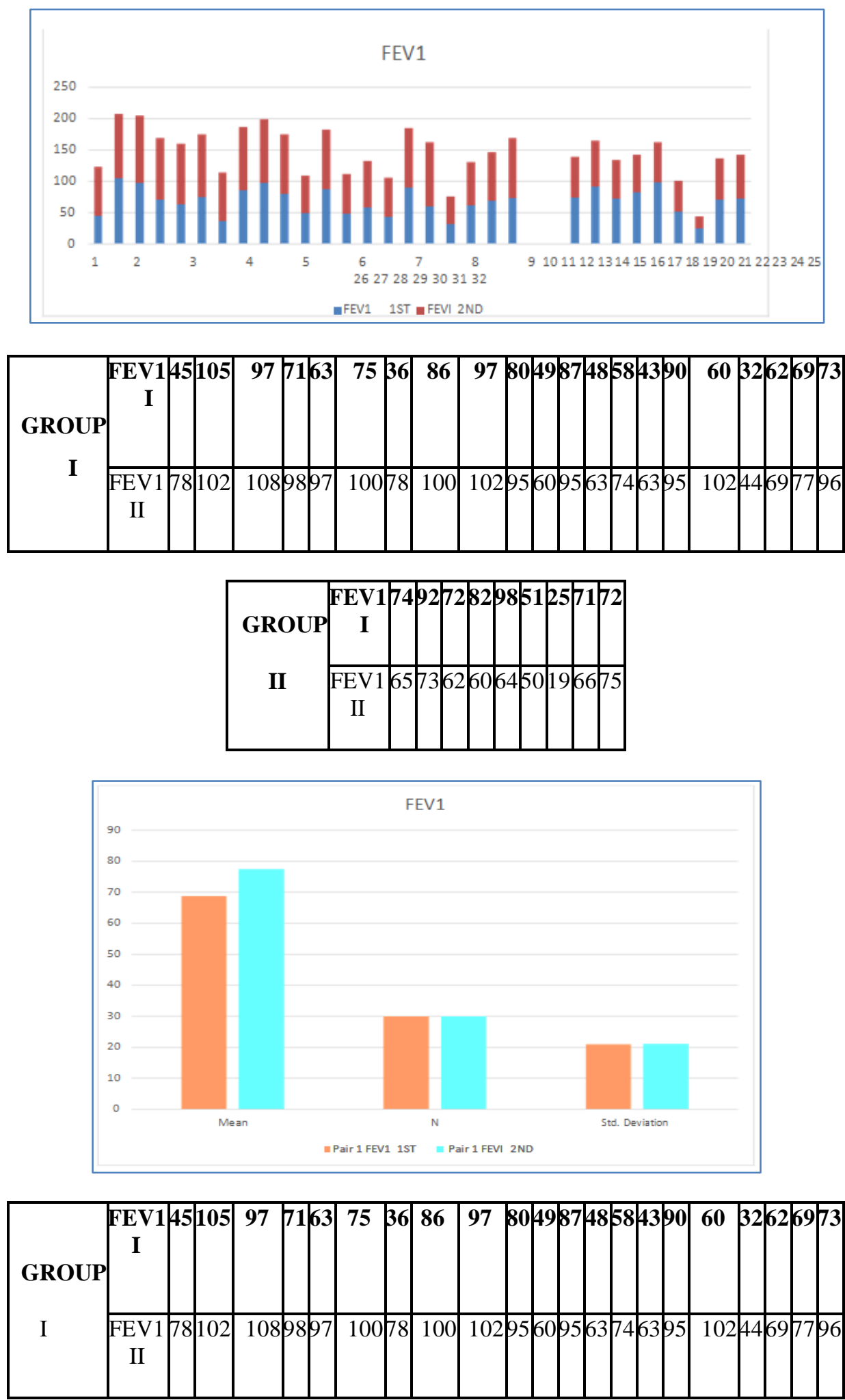

\begin{tabular}{|c|c|c|c|c|c|c|c|c|c|c|}
\hline GROUP & $\begin{array}{l}\text { FEV1 } \\
\text { I }\end{array}$ & 74 & 92 & 72 & 82 & 98 & 51 & 25 & 71 & 72 \\
\hline II & $\begin{array}{c}\text { FEV1 } \\
\text { II }\end{array}$ & 65 & 73 & 62 & 60 & 64 & 50 & 19 & 66 & 75 \\
\hline
\end{tabular}



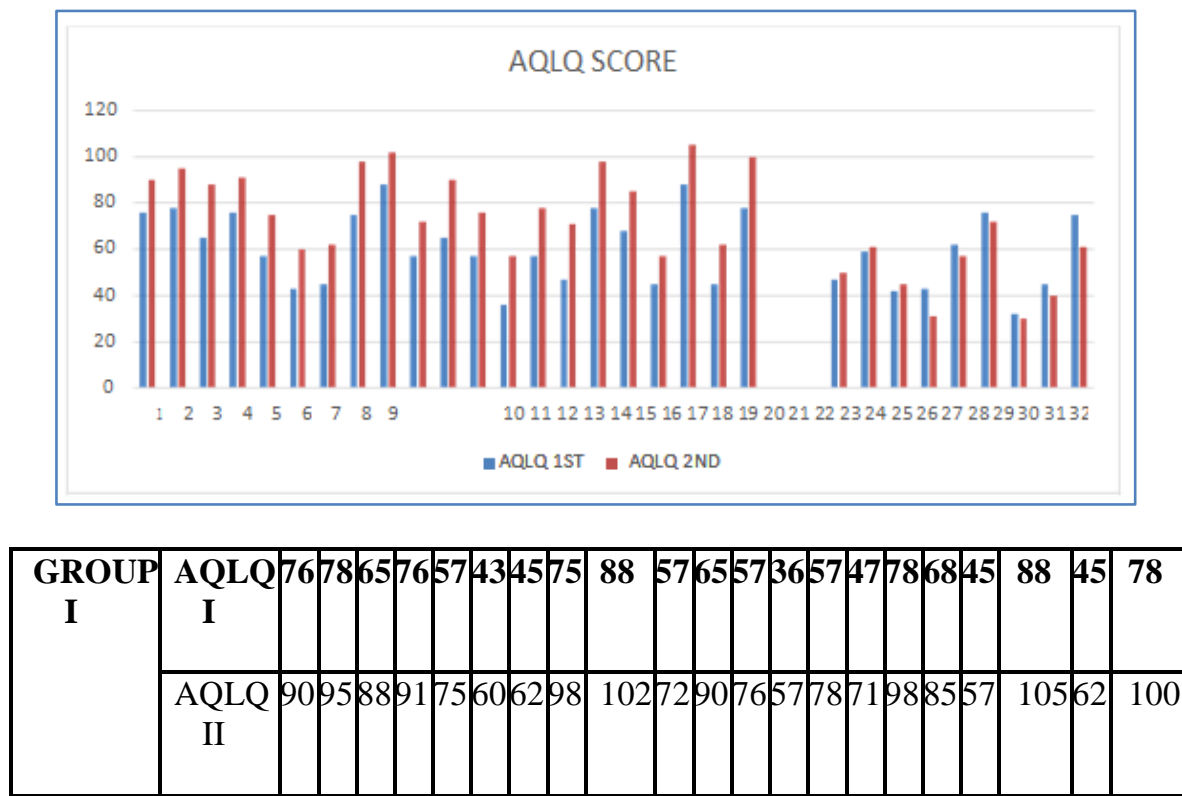

\begin{tabular}{|c|c|c|c|c|c|c|c|c|c|c|}
\hline $\begin{array}{c}\text { GROUP } \\
\text { II }\end{array}$ & $\begin{array}{c}\text { AQLQ } \\
\text { I }\end{array}$ & $\mathbf{4 7}$ & $\mathbf{5 9}$ & $\mathbf{4 2}$ & $\mathbf{4 3}$ & $\mathbf{6 3}$ & $\mathbf{7 6}$ & $\mathbf{3 2}$ & $\mathbf{4 5}$ & $\mathbf{7 5}$ \\
& $\begin{array}{c}\text { AQLQ } \\
\text { II }\end{array}$ & 50 & 61 & 45 & 31 & 57 & 72 & 30 & 40 & 61 \\
& & & & & & & & & & \\
\hline
\end{tabular}

\begin{tabular}{|c|c|c|c|c|}
\hline \multicolumn{2}{|c|}{ T- test } & Mean & $\mathbf{N}$ & $\begin{array}{c}\text { Std. } \\
\text { Deviation }\end{array}$ \\
\hline \multirow{2}{*}{ Pair 1 } & $\begin{array}{c}\text { FEV1 } \\
1 S T\end{array}$ & 68.77 & 30 & 20.99 \\
\cline { 2 - 5 } & FEVI & 77.5 & 30 & 21.182 \\
& 2ND & & & \\
\hline
\end{tabular}

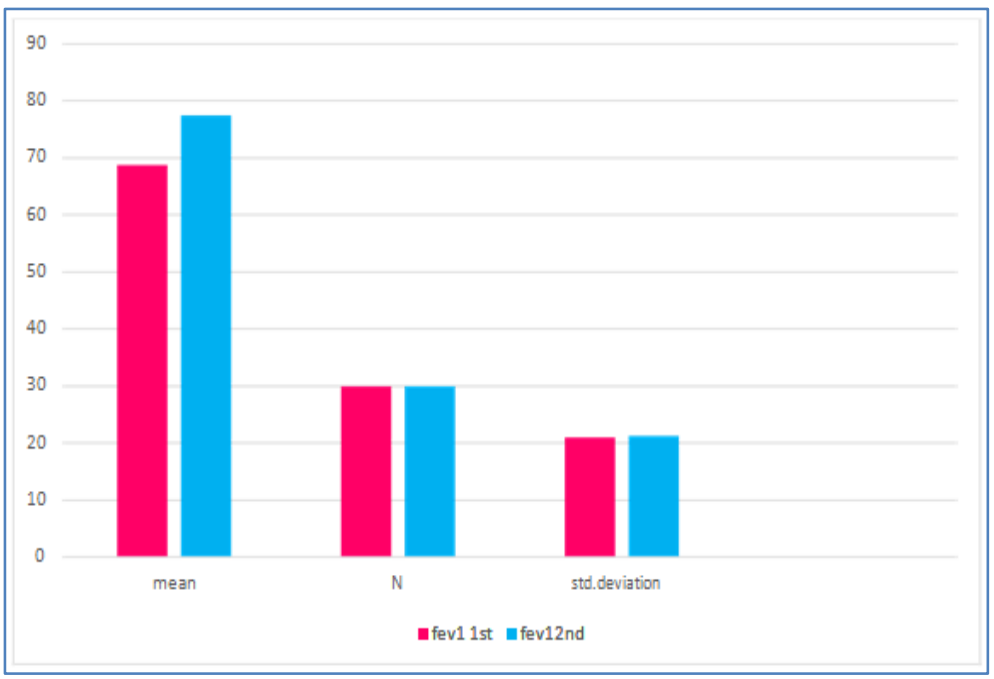




\begin{tabular}{|l|r|r|r|r|}
\hline & \multicolumn{1}{|c|}{ Mean } & N & \multicolumn{1}{|l|}{ Std. Deviation } \\
\hline \multirow{2}{*}{ Pair 1 } & FEV1 $1^{\text {ST }}$ & 68.77 & 30 & 20.990 \\
\cline { 2 - 5 } & FEVI 2 & 77.50 & 30 & 21.182 \\
\hline
\end{tabular}

There was a significant improvement in PFT (increase in FEV1, FEV1/FVC) and the mini AQLQ scoring if the patient has followed the prescribed inhaler with proper inhaler technique and therapeutic breathing exercises.

\section{DiscuSSION}

In this study Inhaler technique and exercises was taught to the 30 patients in which 21 patients were females and 9 were males who were diagnosed with bronchial asthma are included

In these 30 patients with bronchial asthma 5 patients are smokers, 13 patients were using their prescribed inhalers, out of which 5 patients were using it in correct technique and 8 were not using it correctly.

On the first day of visit PFT was done to all the patients in sitting position, FEV1 values are noted. History of allergy, occupation, medication used is also obtained from the patient. Mini AQLQ questionnaire containing 15 questions regarding the level of asthma and limitations of daily activity is provided to the patient and severity scoring is calculated. Proper inhaler technique and breathing exercises was taught to the patient.

On comparing the mini AQLQ and the FEV1 values of first day

9 patients were severely impaired

7 patients were moderately impaired,

6 patients were mild impaired

8 patients were very mild impaired.

He patients were instructed to revisit on the $3^{\text {rd }}$ week, PFT was done and mini AQLQ questionnaire was given to the patient to verify the improvement. 27 patients were using the proper inhaler technique at the end of $3^{\text {rd }}$ week. On comparing mini AQLQ and the FEV1 values

1 patient was very severely impaired

3 patients were severely impaired

5 patients were moderately impaired

8 patients were mild impaired

6 patients were very mild impaired

7 patients were not at all impaired
At the end of the third week 21 patients had improved and 9 patients had not improved.

\section{CONCLUSION}

Bronchial asthma is a very common disease. It is diagnosed based on the clinical and spirometric data. But these are not sufficient to assess the severity of the disease, mini AQLQ questionnaire is used to assess the quality of life of patients diagnosed with bronchial asthma. Educating the patient about disease and teaching inhaler technique, breathing exercise resulted in more improvement in both PFT and quality of life of asthma patients with significant improvement in lung function.

\section{REFERENCE}

1. Juniper, E. F., Guyatt, G. H., Epstein, R. S., Ferrie, P. J., Jaeschke, R., \& Hiller, T. K. (1992). Evaluation of impairment of health related quality of life in asthma: development of a questionnaire for use in clinical trials. Thorax, 47(2), 76-83.

2. Juniper, E. F., Guyatt, G. H., Ferrie, P. J., \& Griffith, L. E. (1993). Measuring quality of life in asthma. American Review of Respiratory Disease, 147, 832-832.

3. Rutten-van Molken, M. P., Custers, F., Van Doorslaer, E. K., Jansen, C. C., Heurman, L., Maesen, F. P., \& Raaijmakers, J. A. (1995). Comparison of performance of four instruments in evaluating the effects of salmeterol on asthma quality of life. European Respiratory Journal, 8(6), 888-898.

4. Rowe, B. H., \& Oxman, A. D. (1993). Performance of an asthma quality of life questionnaire in an outpatient setting. American Review of Respiratory Disease, 148, 675-675.

5. Leidy NK, Coughlin C. Psychometric performance of the Asthma Quality of Life Questionnaire in a US sample. Qual Life Res 1998; 7: 127士134.

6. Sanjuas, C., Alonso, J., Sanchis, J., Casan, P., Broquetas, J. M., Ferrie, P. J., ... \& Anto, J. M. (1995). The quality-of-life questionnaire with asthma patients: the Spanish version of the Asthma Quality of Life Questionnaire. Archivos de bronconeumologia, 31(5), 219-226.

7. Coste, J., Guillemin, F., Pouchot, J., \& Fermanian, J. (1997). Methodological approaches to shortening 
composite measurement scales. Journal of clinical epidemiology, 50(3), 247-252.

8. Juniper, E. F., Johnston, P. R., Borkhoff, C. M., Guyatt, G. H., Boulet, L. P., \& Haukioja, A. (1995). Quality of life in asthma clinical trials: comparison of salmeterol and salbutamol. American journal of respiratory and critical care medicine, 151(1), 66-70.

9. Juniper, E. F., Buist, A. S., Cox, F. M., Ferrie, P. J., \& King, D. R. (1999). Validation of a standardized version of the Asthma Quality of Life Questionnaire. Chest, 115(5), 1265-1270.

10. Juniper, E. F., Guyatt, G. H., Streiner, D. L., \& King, D. R. (1997). Clinical impact versus factor analysis for quality of life questionnaire construction. Journal of clinical epidemiology, 50(3), 233-238.

11. Juniper, E. F., $\mathrm{O}^{\prime}$ byrne, P. M., Guyatt, G. H., Ferrie, P. J., \& King, D. R. (1999). Development and validation of a questionnaire to measure asthma control. European respiratory journal, 14(4), 902-907.
12. Stewart, A. L., Hays, R. D., \& Ware, J. E. (1988). The MOS short-form general health survey: reliability and validity in a patient population. Medical care, 26(7), 724-735.

13. Bousquet, J., Knani, J., Dhivert, H., Richard, A. L. A. I. N., Chicoye, A. N. N. I. E., Ware Jr, J. E., \& Michel, F. B. (1994). Quality of life in asthma. I. Internal consistency and validity of the SF-36 questionnaire. American journal of respiratory and critical care medicine, 149(2), 371-375.

14. Guyatt, G., Walter, S., \& Norman, G. (1987). Measuring change over time: assessing the usefulness of evaluative instruments. Journal of Clinical Epidemiology, 40(2), 171-178.

15. Juniper, E. F., Guyatt, G. H., Willan, A., \& Griffith, L. E. (1994). Determining a minimal important change in a disease-specific quality of life questionnaire. Journal of clinical epidemiology, 47(1), 81-87.

16. Fayers, P. M., \& Hand, D. J. (1997). Factor analysis, causal indicators and quality of life. Quality of Life Research, 6(2), 0-0. 